\title{
Optimization of the Seaport Facilities in Complex System Queue Using Fuzzy Logic
}

\author{
Agus Budiono \\ Department of Physics, Faculty of Science and Technology, Islamic State University Syarif Hidayatullah, Jl. Ir. \\ H. Juanda 95 Ciputat, Indonesia
}

\begin{abstract}
As is well known, that the queuing system model of ships in port plays an important role in efforts to improve the quality of service. Therefore, when used in accordance queuing system and supported by the provision of adequate support facilities it can be ascertained that the services that can be provided would be optimal. In this paper, we will report the results of research on the optimization of port facilities in the complex queuing system using fuzzy logic. We have been developing a methodology optimization of port facilities by a modeling queuing systems and simulation where the system queue complex usually consists of multiple servers connected to a particular system and has a different behavior, among which the pattern of arrival of the vessel, type of service and pattern of services provided. Calculation of seaport facilities optimization with fuzzy logic models using the arrival of the ship has a Poisson distribution of patterns while the service time has an exponential distribution pattern with unlimited resources. We found that fuzzy model is relatively faster than the existing mathematical model and fuzzy model has a high flexibility for all possible inputs are provided compared to the mathematical model.
\end{abstract}

Keywords : Complex System Queue, Erlang distribution, Fuzzy model, Poisson distribution, Seaport.

\section{Introduction}

Optimization of a port facility can be done with different methods of approach, among others; in terms of the problem of transport systems in the port, ship planning system, and the stacking logistics systems and warehousing. The transportation system in the port consists of horizontal transport and stacking. The horizontal transportation system can be divided into Quayside (sea to land or vice versa) that apply to loading and unloading of the ship and land-side systems (land, such as trucks and forklifts) used for stacking and warehouse. Problems Quayside, Bruno et.al. [1] discuss about problem of the propagation and control of autumated guided vehicle, while Kim and Kim [2] discusses the path straddle carrier at the container terminal. Powell and Carvalho [3] discusses the current optimization Flatcar, while Kim et.al. [4] discusses the optimization of the truck at a container terminal in the field. Kim and Kim [5] discusses the problems single-track gantry crane for container. Planning the ship can be divided into several discussions of the issue of the allocation of mooring and ship scheduling, planning of goods, and the separation of cranes. Some papers that discuss the allocation of mooring them is Lie et.al. [6], Park Y-M and Kim K.H. [7]. For the ship scheduling problem itself has been discussed by several authors such as Lim A [8], Nishimura et.al. [9], and Legato P and Mazza R M [10] that the discussion using the queuing system network. One commonly used optimization concept is the concept of minimum total cost. Optimization level is determined by finding the condition in which the amount of costs to be incurred by the manager and the user is at the smallest value. The model of minimum total cost is a method that can be used to determine the optimal level of services and the capacity of the dock optimal considering the components of port charges and the cost of ship time. In Figure 1 it can be seen how the contribution of the service charge and the cost of waiting to the total cost of the harbor. The optimum number of facilities that achieved when the total cost of the minimum port. Lie C.L.et.al. [6] have discussed a scheduling problem with the pattern of multiple job-on-one-processor with a goal to minimize the distance between the scheduling. A ship can be represented as a job, and the processor is interpreted as a mooring. Computational experiments shows how the effectiveness of heuristic method with nearly optimal results. Legato and Mazza [10] discusses the network queuing model (network) with simulation of logistics processes include arrival, tethering, and the departure of the container terminal. 


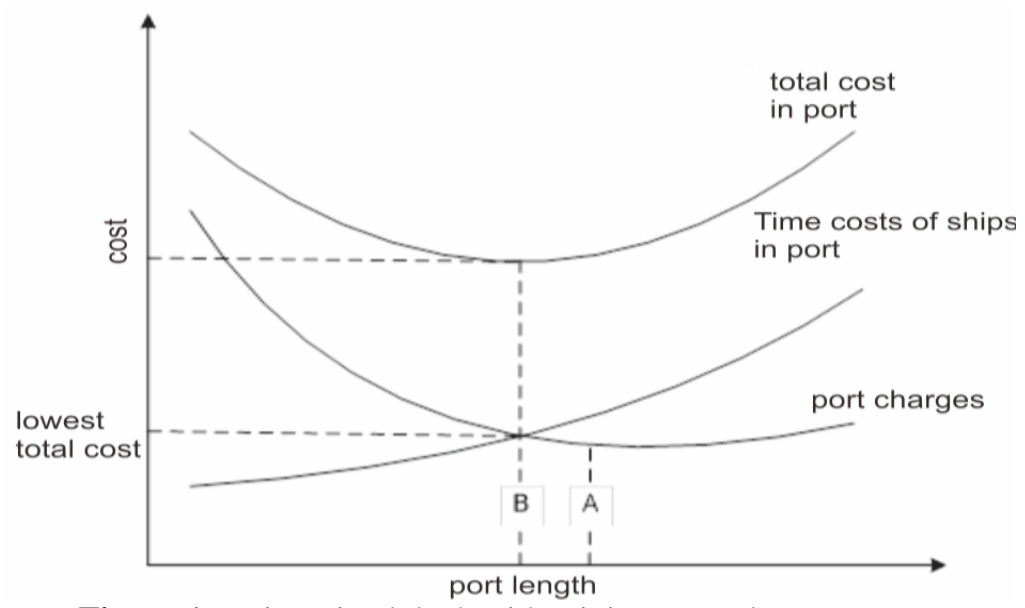

Figure 1. Unit optimal dock with minimum total cost concept

Nishimura et.al. [9] focuses on the problem of dynamic tethering arrangement for tethering systems ship in general (not specific container port, the results of which are shown not in accordance with most container ports in some countries). Heuristic procedures are developed based on the method of Genetic Encryption (GA) so that it can adapt to the real application.

Imai et al [11] studied the allocation of tethering and tethering optimizing utilization by using a heuristic procedure based on the version of static and dynamic formula Mixed Integer Programming (MIP) of the allocation problem and Lagrangian relaxation. The same author also developed a heuristic procedure based GA to solve nonlinear problems of allocation of the priority tethering vessel with different services. In another article, the Imai et.al, connect the tethering allocation by scheduling engine problems, and discuss issues biobjektif nonlinear optimization taking into account the waiting times for vessels and terminal utilization.

Kim and Moon [4] formulate a model of MIP to determine the retention time and the position of the vessel in the container port with a straight-line tethering and develop algorithms SA (Simulated Annealing) so as to obtain an almost optimal results.

Model service priority to be addressed in this study is a model of PR and NP priority. Priority PR is used for conditions in which the type of goods carried have a very short endurance effort should be unloaded from the ship. In this condition, when the ship came to have a higher priority than the vessel being received services, the ship must park out queue even though the process of loading and unloading services unfinished.

NP priority is used for conditions in which the type of goods carried durability, long enough so that it can survive some time before it is unloaded from the ship. In this condition, when the ship came to have a higher priority than the vessel being awarded a service, then the ship came to be waiting for the service to complete.

Based on some research that has been described above on how to perform the optimization of a port, in this paper, we will discuss the optimization problem harbor in terms of a model system in which the ship queue queue management strategy used by a service priority queue discipline on a particular vessel. Giving priority addressed to the vessel containing certain types of goods of basic needs, so that these vessels should receive priority service in advance even though it was the last ship.

\section{A. Optimization Modeling of Ports}

\section{Theoretical Background}

The purpose of making a queuing system model representation is to describe the condition of the system so that it can be analyzed and controlled in order to run properly. In this section, we will discuss about how the presentation queuing system model using mathematical models and fuzzy logic models.

\section{Mathematical Model}

The rate of arrival of the vessel $(\lambda)$ is defined as the number of ships coming to the server at specified intervals. In theory queuing system, usually the pattern of arrival of the vessel to follow a Poisson distribution:

$$
f(x, \lambda)=\frac{\lambda^{x}}{x !} e^{-\lambda}
$$

where $\lambda$ rate of arrival of the vessel, whereas $\mathrm{x}$ is time interval. 
The rate of ship service $(\mu)$ is defined as the average number of vessels that can be served by the server within a certain time interval. In queuing theory, the average service server generally follows the pattern of an exponential distribution:

$$
f(x, \mu)=\frac{1}{\mu} e^{\frac{x}{\mu}}
$$

where $\mu$ is the average value of the data in this case the average service time and $\mathrm{x}$ is time interval. Model of the appropriate queue can be determined by considering the pattern of distribution of the number of arrival and time of service of the vessel.

One of the mathematical calculation models of queuing system parallel with a single server with a model $\mathrm{M} / \mathrm{M} / \mathrm{C}$ is as follows. The probability of the server must wait for the vessel or not serving can be calculated by:

$$
P_{0}=\frac{1}{\left(\sum_{n=0}^{C-1} \frac{1}{n !} \cdot\left(\frac{\lambda}{\mu}\right)^{n}+\frac{1}{C ! \cdot(1-\lambda / \mu \cdot C)} \cdot\left(\frac{\lambda}{\mu}\right)^{C}\right)}
$$

where:

$$
\begin{array}{ll}
\mathrm{P}_{0} & =\text { the probability of a server is not serving } \\
\mathrm{C} & =\text { the server may wait } \\
\lambda & =\text { the number of servers in the queuing system } \\
\mu & =\text { the average number of ship arrivals per unit time }
\end{array}
$$

$\left(\mathrm{L}_{\mathrm{q}}\right)$ is,

The average the vessel waiting for service facilities or the average number of vessels in a path queue

$$
L_{q}=\frac{\left(\frac{\lambda}{\mu}\right)^{C+1}}{C \cdot C ! \cdot(1-\lambda / \mu \cdot C)^{2}} \cdot P_{0}
$$

While the number of vessels in the queue system $\left(\mathrm{L}_{\mathrm{w}}\right)$ is calculated by:

$$
L_{w}=L_{q}+\lambda / \mu
$$

Thus, for the queuing system $\mathrm{M} / \mathrm{M} / \mathrm{C}$, the average level of usage $\rho$ server can be determined by:

$$
\rho=\frac{\lambda}{\mu \cdot C}
$$

One other distribution patterns that can be used in the service system is the Erlang distribution patterns with $r$ phase denoted by $\mathrm{E}_{\mathrm{r}}$ services and the distribution function is expressed as follows:

$$
f(t)=e^{-k \lambda t} \sum_{n=0}^{r-1} \frac{(k \lambda t)^{n}}{n !}
$$

Utility server for the queuing system with Poisson arrival pattern and the Erlang service pattern can be determined by the following equation:

$$
\begin{aligned}
& \rho=\lambda \cdot \frac{r}{\mu}, \quad \text { for the queue model, } \mathrm{M} / \mathrm{E}_{\mathrm{r}} / 1 \\
& \rho=\frac{\lambda}{C} \cdot \frac{r}{\mu}, \quad \text { for the queue model, } \mathrm{M} / \mathrm{E}_{\mathrm{r}} / \mathrm{C}
\end{aligned}
$$

The distribution of the number of vessels in a queue system can be determined using the equation: 


$$
\begin{aligned}
q_{i} & =\sum_{n=(i-1) r+1}^{i r} p_{n} \\
& =\sum_{n=(i-1) r+1}^{i r} \sum_{k=1}^{r} c_{k} x_{k}^{n} \\
& =\sum_{k=1}^{r} \sum_{n=(i-1) r+1}^{i r} c_{k} x_{k}^{n} \\
& =\sum_{k=1}^{r} c_{k}\left(x_{k}^{-r+1}+x_{k}^{-r+2}+\cdots+1\right)\left(x_{k}^{r}\right)^{i}
\end{aligned}
$$

where,

$$
\begin{aligned}
p_{n} & =\sum_{k=1}^{r} c_{k} x_{k}^{n}, \quad n=0,1,2, \ldots \\
c_{k} & =\frac{1-\rho}{\prod_{j \neq k}\left(1-x_{j} / x_{k}\right)}, \quad k=1, \ldots, r,
\end{aligned}
$$

The average waiting time for a single server $\mathrm{T}_{\mathrm{q}}$ is calculated by:

$$
T_{q}=\frac{\rho}{1-\rho} \cdot \frac{r+1}{2} \cdot \frac{1}{\mu}
$$

and the average number of the vessel waiting in a queue $\mathrm{L}_{\mathrm{q}}$ :

$$
T_{q}=\frac{\rho}{1-\rho} \cdot \frac{r+1}{2} \cdot \frac{1}{\mu}
$$

\section{Fuzzy Model}

Fuzzy model of queuing system has the same basic principle with the mathematical queuing system, namely the average parameters arrivals, follow a Poisson distribution and service pattern that follows an exponential distribution. The difference is in how to present these two parameters that can be used to describe the actual queuing system. One of the parameters that contribute in the modeling of the fuzzy queuing system is the use of a server-level parameters. The rate of application or server utilization $(\rho)$ stated amount of time required by the server to serve all vessels in comparison to the amount of time provided by the server to serve aboard. If the value $\rho$ smaller than 1 , it can be said that the server can still serve aboard. But if $\rho$ is greater than 1 , then there is the server experiencing overload. In this condition, the server can not serve all the vessels coming. Parameter $\rho$ in the queuing system is expressed in the form of fuzzy set membership functions. One example $\rho$ modeling on a queue system fuzzy by Zhang et.al. [12] can be seen in Figure 2. In this figure, $\rho$ has a member function that consists of four fuzzy sets were each presented with a linguistic value ZO (zero), PS (positive small), PM (positive medium) and PB (positive big). Each linguistic value has a different intervals so that it can be used to describe the condition of the fuzzy queuing system.

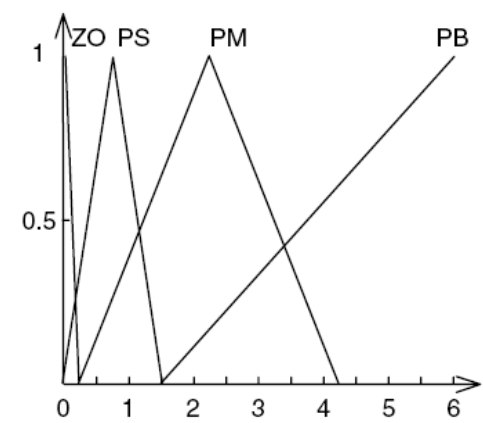

Figure 2. Model of the membership function of $\rho$.

According to Li-Xing Wang [13], some of the reasons are the background why the control with fuzzy logic very well be used to control a queue is as follows:

1. The conventional control theory is so well developed, but the success rate is highly dependent on the quality control system model. The queuing system is usually difficult to describe using mathematical models. 
Although this can be done, but usually the description is formed will be very complex and difficult to analyze. In the fuzzy control, queuing system does not necessarily require a complex mathematical model to control a queue system. Fuzzy control will be fixed according to a complex system for support by the experience, knowledge, and learning from the operator.

2. The fuzzy control is in accordance with highly nonlinear system, as in the case of a queuing system. This leads to fuzzy control is more effective than the other control models.

3. The completion of analytical control queues that already exists only for simple cases. As for a very complex problem, the solution may not be used as an analytical approach. One approach to resolving most probable is using fuzzy control.

4. In the fuzzy queuing system, the average arrival and service levels expressed by fuzzy linguistic variables. Under certain conditions, this statement can truly represent the real conditions when compared to other queuing systems.

\section{Model of M/E2/1}

Description of queuing system model M / E2 / 1:

The pattern of inter-arrival time Poisson,

1. The pattern of inter-service time with 2-phase Erlang services, in which each phase has a level of service that follows an exponential distribution,

2. The number of servers each server capacity is infinite,

3. The number of vessels is infinite.

\section{Model of M / Er / 1 - PR (2 classes)}

The probability of equilibrium equations for a single server queuing system M / Er / 1 to 2 classes using PR priorities are as follows:

$$
\begin{aligned}
& P_{00}\left(\lambda_{1}+\lambda_{2}\right)=P_{10} \mu_{1}+P_{01} \mu_{2} \\
& P_{0, n}\left(\lambda_{1}+\lambda_{2}+\mu_{2}\right)=P_{1, n} \mu_{1}+P_{0, n+1} \mu_{2} ; n=1,2, \ldots, r-1 \\
& P_{0, n}\left(\lambda_{1}+\lambda_{2}+\mu_{2}\right)=P_{0, n-r} \lambda_{2}+P_{1, n} \mu_{1}+P_{0, n+1} \mu_{2} ; n=r, r+1, \ldots \\
& P_{m, n}\left(\lambda_{1}+\lambda_{2}+\mu_{1}\right)=P_{m+1, n} \mu_{1} ; m=1,2, \ldots, r-1 \text { and } n=0,1, \ldots, r-1 \\
& P_{m, n}\left(\lambda_{1}+\lambda_{2}+\mu_{1}\right)=P_{m, n-r} \lambda_{1}+P_{m+1, n} \mu_{1} ; m=1,2, \ldots, r-1 \text { dan } n=r, r+1, \ldots \\
& P_{m, n}\left(\lambda_{1}+\lambda_{2}+\mu_{1}\right)=P_{m-r, n} \lambda_{1}+P_{m+1, n} \mu_{1} ; m=r, r+1, \ldots \text { dan } n=0,1, \ldots, r-1 \\
& P_{m, n}\left(\lambda_{1}+\lambda_{2}+\mu_{1}\right)=P_{m-r, n} \lambda_{1}+P_{m, n-r} \lambda_{2}+P_{m+1, n} \mu_{1} ; m=r, r+1, \ldots \text { and } n=r, r+1, \ldots
\end{aligned}
$$

\section{Model of M / Er / C}

More complex queuing model is the model many servers with the number of servers $\mathrm{C}$. The model consists of one track queue (waiting line) and served by the server are arranged in parallel. Figure 2 shows how the multiserver queuing system conditions mentioned above.

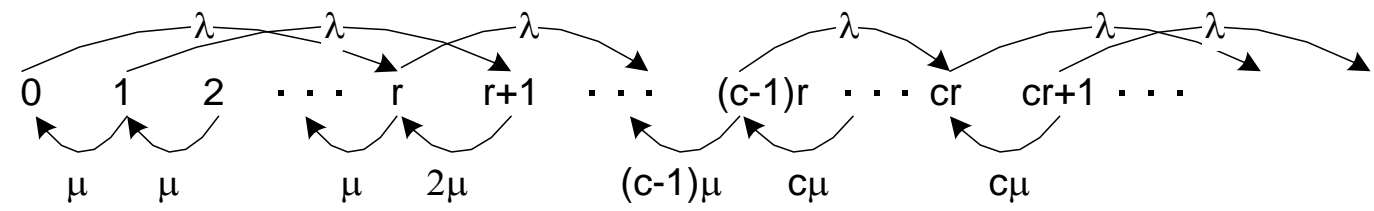

Figure 2. Model of M/Er/C queuing

\section{Model of M/Er/C PR ( 2 classes)}

Server models that will be discussed in this paper is a model multiserver with an Erlang service pattern that consists of two phases using the service and queue discipline LCFS with preemptive resume priority to two types of classification of vessels, i.e vessels type 1 and vessel type 2 . Ship type 1 has priority higher than the vessel type 2. The general form a state diagram for the queuing system with Erlang services and using preemptive resume queue discipline. A state diagram for the multiserver queuing model with Erlang services to r-phase and using a queue discipline PR denoted by M / Er / C PR ( 2 classes) as shown in Figure 3. 


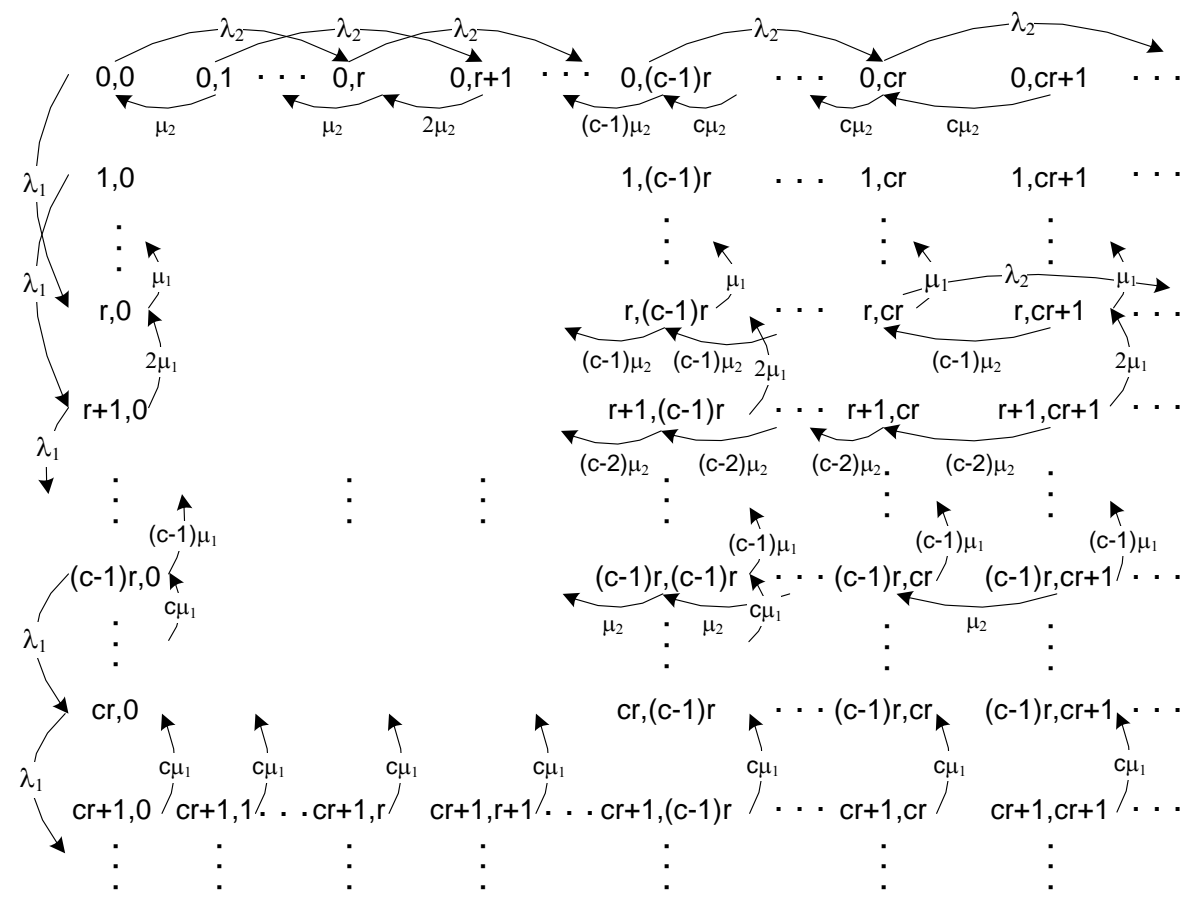

Figure 3. A state diagram of the queue model M / Er / C PR (2 classes).

Figure 3 states the number of phases that must be completed by the server to serve two types of ships, namely types 1 and 2 , where the vessel type 1 has a higher priority than the vessel type 2 . If there are no ships in the queuing system, the state is denoted by (0.0). If there is the arrival of a ship type 1 has the arrival rate is $\lambda 1$, then the situation becomes $(r, 0)$ where $r$ is the number of phases of the service to be performed by the server.

During the number of ships coming does not exceed the number of servers available, the rate of the service provided in proportion to the number of ships coming. When the number of ships that come already exceeded the capacity of the server provided the priority queue discipline, where all servers will be prioritized to serve the ship type 1 .

\section{Methods}

Before performing the optimization of port facilities, it needs to be analyzed in advance on the port conditions in general. Analysis and optimization of port facilities can be done by several methods. In this dissertation, the author will focus on analysis and optimization using fuzzy logic. Basic knowledge of general management system applied at a port of each facility should be a primary consideration in doing fuzzy logic approach. This is because for each policy will impact on the type and number of facilities and infrastructure required by the port.

We have been developing a methodology optimization of port facilities by a modeling queuing systems and simulation where the system queue complex usually consists of multiple servers connected to a particular system and has a different behavior, among which the pattern of arrival of the vessel, type of service and pattern of services provided.

\section{Problem-solving Method}

Some models of service that is widely used in the analysis of queuing theory include service pattern constant, exponential distributions, and the Erlang distribution. To resolve the case of a queue it is necessary to note the form of the distribution function $\mathrm{f}(\mathrm{t})$ and the torque distribution $\mathrm{b}_{\mathrm{n}}$. The parameter value is generally determined based on the following equation:

1. Service time constant

$$
\begin{aligned}
& f(t)= \begin{cases}0, & \text { jika } 0<t<T_{S} \\
1, & \text { jika } t \geq T_{S}\end{cases} \\
& b_{n}=\int_{0}^{\infty} t^{n} d H(t)=\int_{0}^{\infty} t^{n} \delta\left(t-T_{S}\right) d t=T_{S}^{n}
\end{aligned}
$$


2. The service time exponential

$$
\begin{aligned}
& f(t)=1-e^{-t / T_{S}} \\
& b_{n}=\int_{0}^{\infty} t^{n}\left(e^{-t / T_{S}} / T_{S}\right) d t=n ! T_{S}^{n}
\end{aligned}
$$

3. The service time with the r-phase Erlang services

$$
\begin{aligned}
& f(t)=1-e^{-r t / T_{S}}\left(\sum_{k=0}^{r-1} \frac{(r t)^{k}}{k !}\right) \\
& b_{n}=\frac{(n+r-1) !}{(r-1) !}\left(\frac{T_{S}}{r}\right)^{n}
\end{aligned}
$$

\section{Framework of fuzzy queuing models}

The fuzzy logic model framework will be made to solve the optimization problem consists of three models, namely:

1. Model inputs, is a form of set membership is used to represent input data patterns. The model will be made the model inputs include a model of the set for

a. Comparison arrival rate and service rate.

b. Comparison of the cost of waiting and service charges.

2. Output model, a model set of membership that represents the output of the data processing with fuzzy methods that are assertive. The model will be made that the number of membership is set to the number of moorings at the docks optimal.

3. Model inference engine, is the core of fuzzy system on which this model linking a wide variety of combinations of inputs to produce one output for the decisions become fuzzy system. Model inference engine created consists of rules that are used to produce a decision of some input conditions.

Simulations were performed in this study, includes the calculation of the optimal number of facilities on the Quayside mooring performed with fuzzy logic. Simulations are used to queuing system that has been commonly used Java simulation programs that are already available, while the fuzzy simulation and system priority queue used Matlab 7.1 program [14].

\subsection{Results of Modeling System Queue}

\section{Results and DiscussionS}

The results of the modeling queuing system either using or not using the priority in the priority queue discipline listed in Table 1 and Table 2. Table 1 shows that the use of Erlang distribution service with the serious effect of a decrease in waiting times for vessels and vessel queue length. In Table 2 shows how the results of the modeling system using priority queuing preemptive resume the queue discipline. The results show how different the application of a distinct service to the waiting time and queue ship on the same server utilization rate. Services with Erlang distribution provides shorter waiting time and queue length is less than the service using exponential distribution. Based on the comparison of the two tables, it appears that the application

\begin{tabular}{|c|c|c|c|c|c|c|c|}
\hline NO & Distributions & Model & $\rho$ & $\mathbf{L}_{q}$ & $\mathbf{L}_{w}$ & $\mathbf{T}_{\mathrm{q}}$ & $\mathbf{T}_{\mathrm{w}}$ \\
\hline 1 & \multirow[t]{2}{*}{ Exponential } & $\mathrm{M} / \mathrm{M} / 1$ & 0,5 & 0,500 & 1,000 & 0,500 & 1,000 \\
\hline 2 & & $\mathrm{M} / \mathrm{M} / 2$ & 0,5 & 0,000 & 1,337 & 0,168 & 0,669 \\
\hline 3 & \multirow[t]{2}{*}{ Erlang } & $\mathrm{M} / \mathrm{E}_{2} / 1$ & 0,5 & 0,375 & 0,875 & 0,375 & 0,875 \\
\hline 4 & & $\mathrm{M} / \mathrm{E}_{2} / 2$ & 0,5 & 0,129 & 1,258 & 0,129 & 0,629 \\
\hline
\end{tabular}
of the priority queue provides a considerable impact on waiting times for vessels, while for the long queues did not leave substantial influence.

Table 1. The results of some models without priority queue.

\begin{tabular}{|c|c|c|c|c|c|c|c|}
\hline NO & Distributions & Model & $\rho$ & $\mathbf{L}_{\mathbf{q}}$ & $\mathbf{L}_{\mathrm{w}}$ & $\mathbf{T}_{\mathrm{q}}$ & $\mathbf{T}_{\mathrm{w}}$ \\
\hline 1 & \multirow[t]{2}{*}{ Exponential } & $\mathrm{M} / \mathrm{M} / 1 \mathrm{PR}$ & 0,1 & 0,5220 & 1,0224 & 0,0870 & 0,1704 \\
\hline 2 & & $\mathrm{M} / \mathrm{M} / 2 \mathrm{PR}$ & 0,1 & 0,2616 & 0,5233 & 0,0942 & 0,1884 \\
\hline 3 & \multirow[t]{2}{*}{ Erlang } & $\mathrm{M} / \mathrm{E}_{2} / 1 \mathrm{PR}$ & 0,1 & 0,4020 & 0,9030 & 0,0670 & 0,1505 \\
\hline 4 & & $\mathrm{M} / \mathrm{E}_{2} / 2 \mathrm{PR}$ & 0,1 & 0,2355 & 0,4710 & 0,0848 & 0,1696 \\
\hline
\end{tabular}

Data: single server $\left(\lambda_{1}=1\right.$ and $\left.\lambda_{2}=5\right)$; Multiserver $\left(\left(\lambda_{1}=1\right.\right.$ and $\left.\lambda_{2}=5\right)$

Table 2. The results of the model queue with preemptive resume (PR) priority.

Data: single server $\left(\lambda_{1}=1\right.$ and $\left.\lambda_{2}=5\right)$; Multiserver $\left(\left(\lambda_{1}=1\right.\right.$ and $\left.\lambda_{2}=5\right)$ 
Table 3. Calculation results queuing model with non-preemptive (NP) priority.

\begin{tabular}{|l|l|l|l|l|l|l|l|}
\hline NO & Distributions & Model & $\rho$ & $\mathbf{L}_{\mathbf{q}}$ & $\mathbf{L}_{\mathbf{w}}$ & $\mathbf{T}_{\mathbf{q}}$ & $\mathbf{T}_{\mathbf{w}}$ \\
\hline 1 & \multirow{2}{*}{ Exponential } & $\mathrm{M} / \mathrm{M} / 1 \mathrm{NP}$ & 0,1 & 0,5136 & 1,0134 & 0,0856 & 0,1689 \\
\cline { 4 - 9 } & & $\mathrm{M} / \mathrm{M} / 2 \mathrm{NP}$ & 0,1 & 0,2974 & 0,5948 & 0,1570 & 0,2141 \\
\hline 3 & \multirow{2}{*}{ Erlang } & $\mathrm{M} / \mathrm{E}_{2} / 1 \mathrm{NP}$ & 0,1 & 0,3852 & 0,8850 & 0,0642 & 0,1475 \\
\cline { 3 - 8 } & $\mathrm{M} / \mathrm{E}_{2} / 2 \mathrm{NP}$ & 0,1 & 0,2855 & 0,5710 & 0,1028 & 0,2056 \\
\hline
\end{tabular}

Data: single server $\left(\lambda_{1}=1\right.$ and $\left.\lambda_{2}=5\right)$; Multiserver $\left(\left(\lambda_{1}=1\right.\right.$ and $\left.\lambda_{2}=5\right)$

The results of the modeling of the queuing system that uses non-preemptive priority service can be seen in Table 3. In Table 3 shows that differences in the distribution of services impact the waiting time and long queues. A queuing system with Erlang services still provides relatively better results compared with the exponential service. Based on the data in Table 2 and Table 3 shows that the implementation of a priority queue discipline using NP provides relatively better results than PR priority in cases of a single server. Instead, for multiserver case, the application of the priority queue discipline with PR actually provides better results than the use of NP priority. Although the differences in the results are not too significant but it can be predicted that for the priority use cases multiserver PR will provide better results.

\subsection{Optimization of The Seaport with Fuzzy Model}

Calculation of port facilities optimization with fuzzy logic models using the arrival of the ship has a Poisson distribution of patterns while the service time has an exponential distribution pattern with unlimited resources. The data needed to optimize a dock at the port, are:

1. The average number of ship arrivals per day.

2. The average level of service of the vessel at the dock of one unit per day.

3. Fees waiting and service charges of ship in the harbor.

On the optimization of port facilities used by the Mamdani method of FIS. After doing the analysis and testing of the relationship between each of the input data with the expected results, it can be obtained fuzzy logic models that can be applied to all ports. A fuzzy logic model that was formed consisting of a model set of membership for input and output variables, fuzzy rules and implication functions are used, and the method defuzzy. All set membership is for input and output variables declared in five linguistic, namely zero $(\mathrm{N})$, small $(\mathrm{K})$, medium (M), large (B), and very large (SB). Modeling of fuzzy sets for the input variables consist of two modeling, namely, model sets membership to the ratio of the rate of arrival of the vessel $(\lambda)$ to the ship waiter rate $(\mu)$ represented by the symbol RHO $(\mathrm{RHO}=\lambda / \mu)$. Model set membership fees for the comparative value of the vessel waiting ship service charge indicated by the symbol RC. After performing tests on the model set membership and fuzzy rules are applied, then used the method implications min and defuzzy centroid method. As one example, the fuzzy model applies to the Port of Tanjung Perak, as shown in Figure 4 [14]. As a comparison, if the method used is the method FIS Sugeno then obtained a different result, as shown in Figure 5.

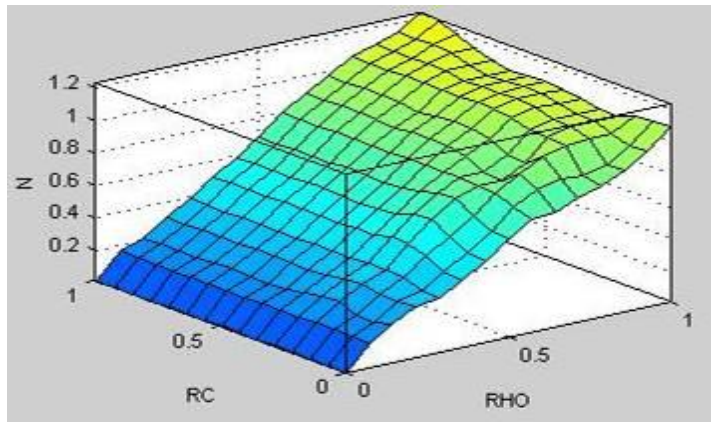

Figure 4. The output of the optimization model FIS Mamdani

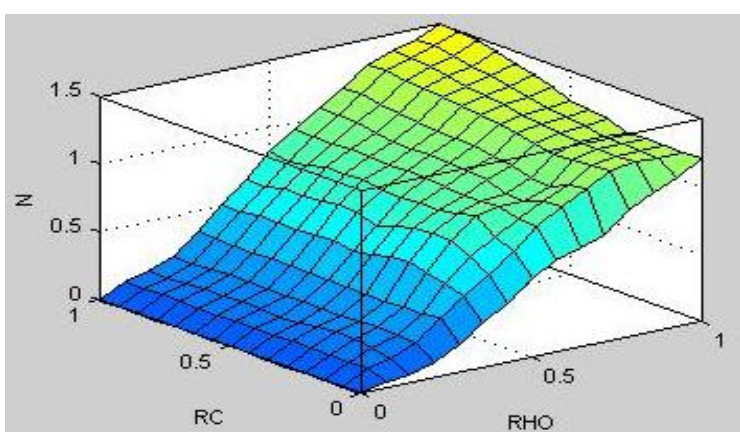

Figure 5. The output of the optimization model FIS Sugeno 
One input is modeled in the queue fuzzy optimization model is the average value of the ratio arrival of the ship and the average ship service. One factor is the reason the researchers chose these parameters as input is that based on the results of testing on some of the approach has been tried, it turns out that value significantly more than the inputs that are still on average arrival of the ship and the average service vessels stand-alone. On a single server queuing system value comparison of average arrivals and average service often referred to by the utility system. In the previous description has stated that the queue fuzzy optimization model in this dissertation uses a multiserver queuing system $\mathrm{M} / \mathrm{M} / \mathrm{C}$, so the comparison value average arrival and servicing of vessels acquired a number of utilities of all servers. To get the average value of the utility of each server, the value must be divided by the number of existing servers. Similarly for the input parameters of the cost factor. In the queue fuzzy optimization model that has been made, modeling the input is not a waiting fee and a service fee ship, but a value comparison between the cost of the reception and the service charge of the ship. Selection of this parameter based on a comparison of these values contributed significantly more than the cost factor and the cost of ships waiting that stands alone. Similarly, the average factor and average arrival of ships. Overall, the use of both input parameters described above cause queues fuzzy optimization model looks much simpler. This is another reason why the researchers used these two parameters. Although the model is not too complex, it does not mean that these models have ignored the original purpose, namely optimization dock at the port facility. Precisely with such fuzzy optimization model queue is expected to further facilitate the planning of port management in the development of ports.

\section{Conclusions}

Based on the calculations and analysis has been done, it can be concluded:

5. Calculation of fuzzy model is relatively faster than the existing mathematical model, because it only uses mathematical equations and results can be obtained directly without performing the iteration process

6. Fuzzy model has a high flexibility for all possible inputs are provided compared to the mathematical model. In determining the optimal number of units dock, changes in input variables such as average arrival time of the service, the waiting fee and service fee

\section{References}

[1] Bruno G. , Ghiani G., Improta G, Dynamic posotioning of idle automated guided of vehicles. Journal of Intelligent Manufacturing 11, 2000, 209-215.

[2] Kim K.H., Kim K.Y, Routing straddle carrier for the loading operation of containers using abeam search algorithm. Computers \& Industrial Engineering 36, 1999, 106-136.

[3] Powell W.B., Carvalho T.A. Real-time optimization of containers and flatcars for intermodal operations. Transportation Science 32(2), 1998, 110-126.

[4] Kim K.H., Moon K.C. Berth scheduling by simulated annealing. Transportation Research-B 37(6), 2003, 541-560.

[5] Kim K.Y, Kim K.H , A routing algorithm for a single transfer crane to load export containers into a containership. Computers \& Industrial Engineering 33, 1997, 673-676.

[6] Lie C-L, Cai X, Lee C-Y Schedulling with multiple-job-one-processor pattern. IIE Transactions 30, 1998, $433-445$.

[7] Park Y-M, Kim K.HA, Schedulling methode for berth and quay cranes. OR Spectrum 25, 2003, 1-23.

[8] Lim A, The berth planning problem. Operations Research Letters 22, 1998, 105-110.

[9] Nishimura E, Imai A, Papadimitriou, Berth allocation planning in the public berth system by genetic algorithms. European Journal of Operational Research 131, 2001, 282-292.

[10] Legato P, Mazza R M, Berth planning and resources optimization in a container terminal via discrete even simulation. European Journal of Operational Research 133, 2001, 537-547.

[11] Imai A, Nishimura E, Papadimitriou The dynamic berth allocation problem for a container port. Transportation Research-B 35(4), 2001, 401-417.

[12] Zhang, R., Phillis, Y.A., Kouikoglou, V.S. (2004) Fuzzy Control of Queuing System. Springer-Verlag, London

[13] Li-Xing Wang, 1997, A Course in Fuzzy Systems and Control, Prentice Hall PTR, Singapore

[14] Budiono A, The Development of a Queuing Model for Optimization of Seaport Facilities at Tanjung Perak Seaport, Indonesia, IOSR Journal of Mechanical and Civil Engineering (IOSR-JMCE), Volume 13, Issue 6 Ver. V (Nov. - Dec. 2016), PP 93-100. 